\title{
D Vitamini Düzeyleri ile İnflamasyon Belirteçleri Arasındaki İlişkinin Değerlendirilmesi
}

\author{
Evaluation of the Relationship Between Vitamin D Levels and Inflammation Markers
}

Eren Vurgun

Prof.Dr. Cemil Tașcioğlu Șehir Hastanesi, Tibbi Biyokimya, İstanbul, Türkiye

\section{Özet}

25-hidroksivitamin D (25(OH)D) düzeyleri ile inflamasyon belirteçleri olan C-reaktif protein (CRP), eritrosit sedimantasyon hızı (ESR), lökosit sayısı ve nötrofil/lenfosit (N/L) oranı parametreleri arasındaki ilişkinin incelenmesi amaçlandı. Ek olarak, D vitamini eksikliği olan popülasyondaki inflamasyon belirteçlerinin yüksekliğinin ve eş zamanlı olarak inflamasyon belirteçleri yüksek olan popülasyondaki D vitamini eksikliğinin araştırılması amaçlandı. Eylül 2017 - Mart 2020 tarihleri arasında 18 yaş ve üzerindeki 49166 erişkin hastaya ait eş zamanlı olarak istenmiş olan 25(OH)D, CRP, ESR, lökosit sayısı ve N/L oranı sonuçları retrospektif olarak incelendi. Parameteler arasındaki korelasyonlar ve 25(OH)D eksikliği ve inflamasyon belirteçleri yükseklikleri arasındaki ilişkiler değerlendirildi. İnflamasyon belirteçleri olan CRP, ESR, lökosit sayısı ve NLR ile 25(OH)D arasında zayıf düzeyde ters yönlü korelasyonlar tespit edildi (sırasıyla; $r=-0,077, \mathrm{p}<0.01 ; \mathrm{r}=-0,036, \mathrm{p}<0.01 ; \mathrm{r}=-0,074, \mathrm{p}<0.01$ ve $\mathrm{r}=-0,074, \mathrm{p}<0.01$ ). D vitamini eksiklik sınır değeri olarak $30 \mathrm{ng} / \mathrm{mL}$ kabul edildiğinde, 25(OH)D eksikliği olanların \%63,2'sinde CRP düzeyleri normal iken, CRP yüksekliği olanların \%85,6'sında 25(OH)D eksikliği olduğu saptand $(\mathrm{p}<0,001)$. Benzer olarak 25(OH)D eksikliği olanların \%85,3'ünde lökosit sayısı normal iken, lökosit yüksekliği olanların \%86,6’sında $25(\mathrm{OH}) \mathrm{D}$ eksikliği olduğu saptandı $(\mathrm{p}<0,001)$. Ek olarak, 25(OH)D eksikliği olanların \%42,7'sinde ESR düzeyleri normal iken, ESR yüksekliği olanların \%84,1'inde 25(OH)D eksikliği olduğu saptandı $(\mathrm{p}<0,001)$. Çalışmanın bulguları, $\mathrm{D}$ vitamini düşüklüğünün inflamasyona neden olmasından ziyade $\mathrm{D}$ vitamini düzeylerinin inflamasyonun sonucu olarak düşük olduğu hipotezini desteklemektedir.

Anahtar Kelimeler: D vitamini, inflamasyon, inflamasyon belirteçleri, C-reaktif protein

\section{Abstract}

The aim of this study was to investigate the relationships between 25-hydroxyvitamin D $(25(\mathrm{OH}) \mathrm{D})$ levels and inflammation markers such as C-reactive protein (CRP), erythrocyte sedimentation rate (ESR), leukocyte count and neutrophil/lymphocyte $(\mathrm{N} / \mathrm{L})$ ratio parameters. In addition, it was aimed to investigate the frequency of elevation of inflammation markers in vitamin D deficient population and thus frequency of vitamin $\mathrm{D}$ deficiency in the population with elevated inflammation markers. Simultaneously requested 25(OH)D, CRP, ESR, leukocyte count and N/L ratio results of 49166 adult patients between September 2017 and March 2020 were retrospectively analyzed. The correlations between parameters and the frequencies of 25(OH)D deficiency and elevated inflammation markers were evaluated. Weak inverse correlations were observed between $25(\mathrm{OH}) \mathrm{D}$ and inflammation markers such as CRP, ESR, leukocyte count and NLR ( $r=-0.077, p<0.01 ; r=-0.036, p<0.01 ; r=-0.074, p<0.01$ and $r=-0.074, p<0.01$, respectively). When $<30 \mathrm{ng} / \mathrm{mL}$ considered as the cut-off value for vitamin D deficiency; CRP levels were normal in $63.2 \%$ of those with 25(OH)D deficiency, while $85.6 \%$ of those with elevated CRP levels had $25(\mathrm{OH}) \mathrm{D}$ deficiency $(\mathrm{p}<0.001)$. Similarly, while the leukocyte count was normal in $85.3 \%$ of those with $25(\mathrm{OH}) \mathrm{D}$ deficiency, $86.6 \%$ of those with elevated leukocyte deficiency had $25(\mathrm{OH}) \mathrm{D}$ deficiency $(\mathrm{p}<0.001)$. In addition, while ESR levels were normal in $42.7 \%$ of those with $25(\mathrm{OH}) \mathrm{D}$ deficiency, it was found that $84.1 \%$ of those with elevated ESR had $25(\mathrm{OH}) \mathrm{D}$ deficiency $(\mathrm{p}<0.001)$. The findings of this study support the hypothesis that vitamin D levels are low as a result of inflammation rather than the lower vitamin D levels causes inflammation.

Keywords: vitamin D, inflammation, inflammation markers, C-reactive protein 


\section{Giriș}

Depresyondan kardiyovasküler hastalıklara, kansere ve otoimmün hastalıklara kadar pek çok hastalığın temelinde teoride etiyolojik bir faktör olarak inflamasyonun olduğu düşünülmektedir (1-4). İnflamasyonun ölçümünde C-reaktif protein (CRP) ve eritrosit sedimantasyon hızı (ESR) ve sitokinler gibi inflamasyon belirteçleri kullanılmaktadır (5). Lökosit sayıs1 ve nötrofil/lenfosit (N/L) oranının da kronik hastalıkların inflamasyon sürecini göstermede faydalı olabileceği bildirilmiştir (6).

D vitamini ölçümü son yıllarda tüm dünyada katlanarak artmıştır (7). Ancak D vitamini eksikliğinin tanımı ve sınır değerleri halen tartışılmaktadır. 25(OH)D düzeyleri için olmak üzere; Endokrin Cemiyeti $<20$ ng/mL'yi eksiklik, 20-30 ng/mL arasın1 yetersizlik ve $\geq 30 \mathrm{ng} / \mathrm{mL}$ 'yi yeterli olarak tanımlarken (8), Amerika Tıp Enstitüsü $<12$ ng/mL'yi eksiklik, $12-20 \quad \mathrm{ng} / \mathrm{mL}$ arasını yetersizlik ve $\geq 20 \mathrm{ng} / \mathrm{mL}$ 'yi yeterli olarak tanımlamaktadır (9).

İnflamasyon ve D vitamini arasındaki ilişki ise çok sayıda araştırmacının ilgisini çekmekle beraber tartışmalıdır. Bazı araştırmacılar inflamasyonun 25(OH)D konsantrasyonunu azalttığını öne sürerken (10-12), bazı araştırmacılar ise $\operatorname{artan} 25(\mathrm{OH}) \mathrm{D}$ düzeylerinin inflamasyonu azalttığını öne sürmektedir (13-15).

Bu çalışmada, kesitsel olarak 2,5 yıllık süre zarfında hastanemize başvurmuş olan tüm erişkin popülasyonun $25(\mathrm{OH}) \mathrm{D}$ düzeyleri ile inflamasyon belirteçleri olarak CRP, ESR, lökosit sayıs1 ve N/L oranı parametreleri arasındaki ilişkinin incelenmesi amaçlandi. Ek olarak, D vitamini eksikliği olan popülasyondaki inflamasyon belirteçlerinin yüksekliğinin ve eş zamanlı olarak inflamasyon belirteçleri yüksek olan popülasyondaki $\mathrm{D}$ vitamini eksikliğinin araştırılması amaçlandı.

\section{Gerec ve Yöntem}

\subsection{Veriler}

Eylül 2017 - Mart 2020 tarihleri arasında 18 yaş ve üzerindeki erişkinlerden İstanbul
Prof.Dr. Cemil Taşcioğlu Şehir Hastanesi kliniklerinden eş zamanlı olarak istenmiş olan 25(OH)D, CRP, ESR, lökosit sayısı ve N/L oran1 tetkiklerinin sonuçları retrospektif olarak laboratuvar bilgi yazılım sisteminden (LBYS) tarandı. Kesitsel olan bu çalışma için herhangi bir dışlama kriteri kullanılmayarak yukarıda belirtilen tetkiklerin eş zamanlı istenmiş olduğu tüm kliniklerdeki tüm erişkinlerin sonuçları çalışmaya dahil edildi.

Çalışma için İstanbul Prof.Dr. Cemil Taşcioğlu Şehir Hastanesi Klinik Araştırmalar Etik Kurulu'ndan 26.01.2021 tarihli 29 say1l etik kurul izni alındı.

CRP düzeyleri CRP Latex (Beckman Coulter, USA) kiti kullanılarak AU5800 (Beckman Coulter Diagnostics, Brea, CA, USA) analizöründe; 25(OH)D düzeyleri Access 25(OH)D Total kiti kullanilarak DXI800 (Beckman Coulter Diagnostics, Brea, CA, USA) analizöründe; ESR düzeyleri Westergren metodu ile THERMA NE (Linear Chemicals, Montgat, Spain) analizöründe; lökosit, nötrofil ve lenfosit sayıları ise BC6800 (Shenzhen Mindray Biomedical Electronics, Nanshan, PR China) otomatik tam kan sayım analizöründe ölçülmüş idi.

Sınır değerleri olarak; CRP yüksekliği için $>5$ $\mathrm{mg} / \mathrm{L}$, ESR yüksekliği için erkeklerde $>15$ $\mathrm{mm} / \mathrm{saat}$ ve kadınlarda $>20 \mathrm{~mm} / \mathrm{saat}$, lökosit yüksekliği için $>10 \times 10^{3} / \mu \mathrm{L}$ kullanıldı. $25(\mathrm{OH}) \mathrm{D}$ düzeyinin yeterli olup olmadığ 1 incelenirken ise $<20$ ve $<30 \mathrm{ng} / \mathrm{mL}$ olmak üzere iki farklı sınır değeri de kullanılarak ayrı ayrı değerlendirildi.

\section{2. İstatistiksel Analiz}

Veriler normal dağılım göstermediği için tüm parameteler arasındaki korelasyonlar Spearman korelasyon testi ile incelendi. 25(OH)D eksikliğine göre CRP, ESR ve lökosit yüksekliklerinin karşılaştırılmasında Ki-kare testi kullanıldı. Tüm istatistiksel analizler SPSS 17 (SPSS Inc., Chicago, Illinois, USA) programı kullanılarak yapıldı. Tüm istatistiksel analizlerde $\mathrm{p}<0,05$ anlamlı olarak kabul edildi. 


\section{Bulgular}

Çalışmanın verileri, yaş ortalamaları $51 \pm 18$ olan 35593'si kadın ve 13573'u erkek olmak üzere toplam 49166 kişinin sonuçlarından oluşmakta idi.

İnflamasyon belirteçleri olan CRP, ESR, zayıf düzeyde ters yönlü korelasyonlar tespit edildi (sırasıly; $\mathrm{r}=-0,077, \mathrm{p}<0.01 ; \mathrm{r}=-0,036$, $\mathrm{p}<0.01 ; \quad \mathrm{r}=-0,074, \quad \mathrm{p}<0.01 \quad$ ve $\mathrm{r}=-0,074$, $\mathrm{p}<0.01$ ). İnflamasyon parametrelerinin kendi aralarındaki korelasyonlar ise Tablo 1'de lökosit sayısı ve NLR ile 25(OH)D arasında

Tablo 1: Parametreler arasındaki korelasyonlar

\begin{tabular}{|c|c|c|c|c|c|}
\hline & $25(\mathrm{OH}) \mathrm{D}$ & CRP & ESR & Lökosit sayısı & N/L oranı \\
\hline $25(\mathrm{OH}) \mathrm{D}$ & 1 & $-0,077 *$ & $-0,036^{*}$ & $-0,074 *$ & $-0,074 *$ \\
\hline CRP & & 1 & $0,544^{*}$ & $0,288^{*}$ & $0,310^{*}$ \\
\hline ESR & & & 1 & $0,127^{*}$ & $0,203 *$ \\
\hline Lökosit sayısı & & & & 1 & $0,297 *$ \\
\hline N/L oranı & & & & & 1 \\
\hline
\end{tabular}

İki farklı 25(OH)D sınır değerine göre CRP, ESR ve lökosit yüksekliklerindeki 25(OH)D eksiklik yüzdeleri karşılaştırmalı olarak Tablo 2 ve Tablo 3'de gösterildi.

Tablo 2. Vitamin D eksikliği $(<20 \mathrm{ng} / \mathrm{mL})$ ile CRP, ESR ve lökosit yüksekliklerinin karşılaştırılması

\begin{tabular}{|c|c|c|c|c|c|}
\hline \multirow{4}{*}{ CRP (mg/L) } & \multirow{4}{*}{$\begin{array}{c}\text { Normal } \\
(\leq 5)\end{array}$} & \multirow[b]{3}{*}{ Sayı } & \multicolumn{2}{|c|}{ 25(OH)D (ng/mL) } & \multirow[t]{2}{*}{$\mathbf{p}$} \\
\hline & & & Eksik $(<20)$ & Yeterli $(\geq 20)$ & \\
\hline & & & 16651 & 14650 & \multirow[t]{6}{*}{$<0,001$} \\
\hline & & $\begin{array}{c}\text { CRP normal içerisindeki } \\
\%\end{array}$ & $\% 53,2$ & $\% 46,8$ & \\
\hline \multirow{10}{*}{$\begin{array}{c}\text { ESR } \\
(\mathbf{m m} / \text { saat })\end{array}$} & & $\begin{array}{c}\text { 25(OH)D durumu } \\
\text { içerisindeki \% }\end{array}$ & $\% 61,5$ & $\% 66,4$ & \\
\hline & \multirow{3}{*}{$\begin{array}{c}\text { Yüksek } \\
(>5)\end{array}$} & Sayı & 10442 & 7423 & \\
\hline & & $\begin{array}{c}\text { CRP yüksek içerisindeki } \\
\%\end{array}$ & $\% 58,4$ & $\% 41,6$ & \\
\hline & & $\begin{array}{l}\text { 25(OH)D durumu } \\
\text { içerisindeki \% }\end{array}$ & $\% 38,5$ & $\% 33,6$ & \\
\hline & Normal & Sayı & 11409 & 9427 & \multirow[t]{6}{*}{0,18} \\
\hline & $\begin{array}{l}(\mathrm{K}: \leq \mathbf{2 0} \\
\mathrm{E}: \leq 15)\end{array}$ & $\begin{array}{c}\text { ESR normal içerisindeki } \\
\%\end{array}$ & $\% 54,8$ & $\% 45,2$ & \\
\hline & & $\begin{array}{l}\text { 25(OH)D durumu } \\
\text { içerisindeki \% }\end{array}$ & $\% 42,1$ & $\% 42,7$ & \\
\hline & Yüksek & Sayı & 15684 & 12646 & \\
\hline & $\begin{array}{l}(\mathrm{K}:>20, \\
\mathrm{E}:>15)\end{array}$ & $\begin{array}{c}\text { ESR yüksek içerisindeki } \\
\%\end{array}$ & $\% 55,4$ & $\% 44,6$ & \\
\hline & & $\begin{array}{l}\text { 25 }(\mathrm{OH}) \mathrm{D} \text { durumu } \\
\text { içerisindeki \% }\end{array}$ & $\% 57,9$ & $\% 57,3$ & \\
\hline \multirow{2}{*}{$\begin{array}{c}\text { Lökosit } \\
\text { sayısı } \\
\left(\times 10^{3} / \mu \mathrm{L}\right)\end{array}$} & \multirow{2}{*}{$\begin{array}{l}\text { Normal } \\
(\leq \mathbf{1 0})\end{array}$} & Sayı & 22835 & 19283 & \multirow[t]{2}{*}{$<0,001$} \\
\hline & & $\begin{array}{c}\text { Lökosit sayısı normal } \\
\text { içerisindeki \% }\end{array}$ & $\% 54,2$ & $\% 45,8$ & \\
\hline
\end{tabular}




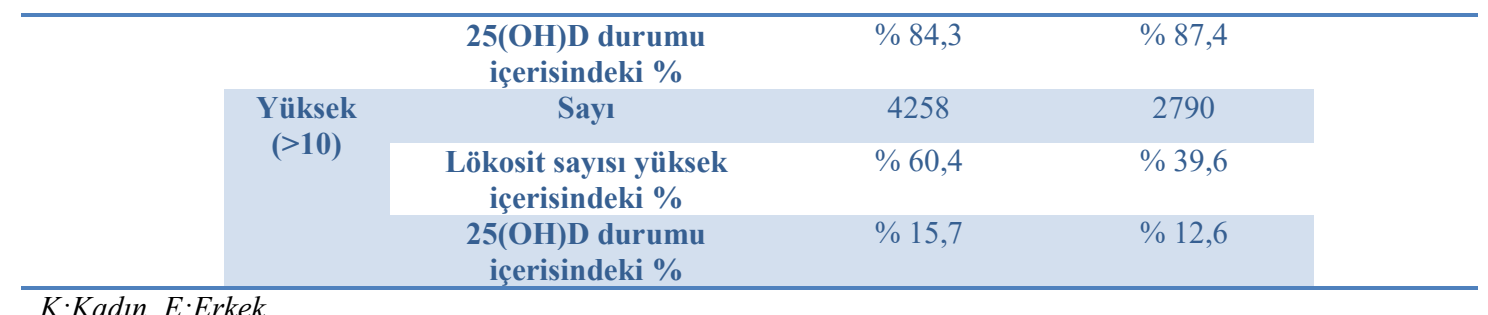

Eksiklik sınır değeri olarak $20 \mathrm{ng} / \mathrm{mL}$ kabul edildiğinde, 25(OH)D eksikliği olanların \%61,5'inde CRP düzeyleri normal iken, CRP yüksekliği olanların $\% 58,4$ 'ünde $25(\mathrm{OH}) \mathrm{D}$ eksikliği olduğu saptandı $(\mathrm{p}<0,001)$. Benzer olarak 25(OH)D eksikliği olanların \%84,3'ünde lökosit sayısı normal iken, lökosit yüksekliği olanların $\% 60,4$ 'ünde $25(\mathrm{OH}) \mathrm{D}$ eksikliği olduğu saptand $1(\mathrm{p}<0,001)$.

Tablo 3. Vitamin D eksikliği $(<30 \mathrm{ng} / \mathrm{mL})$ ile CRP, ESR ve WBC yüksekliklerinin karşılaştırılması

\begin{tabular}{|c|c|c|c|c|c|}
\hline \multirow{4}{*}{$\begin{array}{c}\mathrm{CRP} \\
(\mathrm{mg} / \mathrm{L})\end{array}$} & \multirow{5}{*}{$\begin{array}{c}\text { Normal } \\
(\leq 5)\end{array}$} & & \multicolumn{2}{|c|}{$25(\mathrm{OH}) \mathrm{D}(\mathrm{ng} / \mathrm{mL})$} & \multirow[t]{2}{*}{$\mathbf{p}$} \\
\hline & & & Eksik $(<30)$ & Yeterli $(\geq \mathbf{3 0})$ & \\
\hline & & Sayı & 26294 & 5007 & $<0,001$ \\
\hline & & $\begin{array}{c}\text { CRP normal içerisindeki } \\
\%\end{array}$ & $\% 84,0$ & $\% 16,0$ & \\
\hline & & $\begin{array}{l}\text { 25(OH)D durumu } \\
\text { içerisindeki \% }\end{array}$ & $\% 63,2$ & $\% 66,1$ & \\
\hline & Yüksek & Sayı & 15292 & 2573 & \\
\hline & & $\begin{array}{c}\text { CRP yüksek içerisindeki } \\
\%\end{array}$ & $\% 85,6$ & $\% 14,4$ & \\
\hline & & $\begin{array}{l}\text { 25 }(\mathrm{OH}) \mathrm{D} \text { durumu } \\
\text { içerisindeki \% }\end{array}$ & $\% 36,8$ & $\% 33,9$ & \\
\hline \multirow{6}{*}{$\begin{array}{c}\text { ESR } \\
(\mathbf{m m} / \mathbf{s a a t})\end{array}$} & \multirow{3}{*}{$\begin{array}{c}\text { Normal } \\
(K: \leq 20 \\
E: \leq 15)\end{array}$} & Sayı & 17770 & 3066 & \multirow[t]{6}{*}{$<0,001$} \\
\hline & & $\begin{array}{c}\text { ESR normal içerisindeki } \\
\%\end{array}$ & $\% 85,3$ & $\% 14,7$ & \\
\hline & & $\begin{array}{l}\text { 25(OH)D durumu } \\
\text { içerisindeki \% }\end{array}$ & $\% 42,7$ & $\% 40,4$ & \\
\hline & \multirow{3}{*}{$\begin{array}{c}\text { Yüksek } \\
(K:>20, \\
E:>15)\end{array}$} & Sayı & 23816 & 4514 & \\
\hline & & $\begin{array}{c}\text { ESR yüksek içerisindeki } \\
\%\end{array}$ & $\% 84,1$ & $\% 15,9$ & \\
\hline & & $\begin{array}{l}\text { 25 }(\mathrm{OH}) \mathrm{D} \text { durumu } \\
\text { içerisindeki \% }\end{array}$ & $\% 57,3$ & $\% 59,6$ & \\
\hline \multirow{6}{*}{$\begin{array}{c}\text { Lökosit } \\
\text { sayısı } \\
\left(\times 10^{3} / \mu \mathrm{L}\right)\end{array}$} & \multirow{3}{*}{$\begin{array}{c}\text { Normal } \\
(\leq 10)\end{array}$} & Sayı & 35485 & 6633 & \multirow[t]{6}{*}{$<0,001$} \\
\hline & & $\begin{array}{l}\text { Lökosit sayısı normal } \\
\text { içerisindeki \% }\end{array}$ & $\% 84,3$ & $\% 15,7$ & \\
\hline & & $\begin{array}{c}\text { 25(OH)D durumu } \\
\text { içerisindeki \% }\end{array}$ & $\% 85,3$ & $\% 87,5$ & \\
\hline & \multirow{3}{*}{$\begin{array}{c}\text { Yüksek } \\
(>10)\end{array}$} & Sayı & 6101 & 947 & \\
\hline & & $\begin{array}{l}\text { Lökosit sayısı yüksek } \\
\text { içerisindeki \% }\end{array}$ & $\% 86,6$ & $\% 13,4$ & \\
\hline & & $\begin{array}{l}\text { 25(OH)D durumu } \\
\text { içerisindeki \% }\end{array}$ & $\% 14,7$ & $\% 12,5$ & \\
\hline
\end{tabular}

Eksiklik sınır değeri olarak $30 \mathrm{ng} / \mathrm{mL}$ kabul edildiğinde ise, $25(\mathrm{OH}) \mathrm{D}$ eksikliği olanların \%63,2'sinde CRP düzeyleri normal iken, CRP yüksekliği olanların \%85,6'sında $25(\mathrm{OH}) \mathrm{D}$ 
eksikliği olduğu saptandı $(\mathrm{p}<0,001)$. Benzer olarak 25(OH)D eksikliği olanların \%85,3'ünde lökosit sayısı normal iken, lökosit yüksekliği olanların \%86,6'sında $25(\mathrm{OH}) \mathrm{D}$ eksikliği olduğu saptandı $(p<0,001)$. Ek olarak, 25(OH)D eksikliği olanların \%42,7'sinde ESR düzeyleri normal iken, ESR yüksekliği olanların $\% 84,1$ 'inde $25(\mathrm{OH}) \mathrm{D}$ eksikliği olduğu saptandı $(\mathrm{p}<0,001)$.

\section{Tartışma}

İnflamasyon birçok kronik hastalığın patogenezinde yer almaktadır. Özellikle gözlemsel çalışmalarda inflamatuvar hastalıklar ve düşük serum 25(OH)D düzeyleri arasında ilişki tespit edilmesi, D vitamini eksikliğinin inflamatuvar süreçler üzerindeki etkisi konusundaki şüpheyi artırmıştır. Ancak ileri araştırmaların genel popülasyonun büyük bir kısmında D vitamini düzeylerinin düşük olduğunu ortaya koymas1, bazı otoritelerin $\mathrm{D}$ vitamini eksikliğini dünya çapında epidemik olarak tanımlamasına yol açmışırır (16).

Son dönemlerde pek çok hastalıkta D vitamini düzeyleri ve inflamasyon belirteçleri arasındaki ilişki araştırılmakla birlikte bu çalışmaların çok büyük bir çoğunluğu vakakontrol şeklinde araştırmalar olup hastalık spesifik çalışmalardır. Kesitsel olarak geniş kapsamlı olarak genel popülasyonda bu durumu araştıran daha az sayıda çalışmaya rastlanmıştır (17-20).

Örneklem olarak 49166 erişkini içeren bu kesitsel çalışmada; 25(OH)D düzeyleri ile inflamasyon belirteçleri olan CRP, ESR, lökosit sayısı ve NLR parametreleri arasında ters yönlü korelasyonlar olduğu tespit edildi. Tüm korelasyonlar istatistiksel olarak $p<0,01$ düzeyinde anlamlı olmasına rağmen korelasyon katsayılarının zayıf düzeylerde olduğu gözlendi.

Literatüre baktığımızda; 25(OH)D düzeyleri ile CRP arasında ters yönlü bir korelasyonun bazı çalışmalarda bulunduğu $(17,19-22)$ ancak tüm çalışmalarda bulunmadığı (18) görüldü. Son dönemde yapılmış olan ve 24 farklı hastalıkta 25(OH)D ile CRP arasındaki ilişkinin incelendiği bir başka kesitsel çalışmada da pek çok hastalık grubunda
25(OH)D ile CRP arasında ters yönlü bir ilişki olduğu gösterilmiştir (23). Bu çalışmadaki bulguya benzer olarak, 25(OH)D ile CRP gibi inflamasyon belirteçleri arasında ters bir ilişki tespit edilen çalışmaların büyük çoğunluğundaki korelasyonların zayıf düzeylerde olması, $\mathrm{CRP}$ düzeylerindeki değișimin yalnızca bir kısmını açıklamaktadır. Kruit ve ark. (24) inflamatuvar olan ve inflamatuvar olmayan hastalıklar olarak iki grupta 25(OH)D ve CRP düzeylerini inceledikleri çalışmalarında, her iki grupta da 25(OH)D düzeyleri ile CRP düzeyleri arasında ters yönlü bir korelasyon saptamışlardır. Ek olarak, çalışmalarında her iki grubun 25(OH)D düzeyleri karşılaştırıldığında aralarında bir fark bulunmamış olup, bu durumu da verilerinin düşük 25(OH)D düzeylerinin inflamasyona yatkınlığa katkıda bulunduğu fikrini desteklemediği yönünde değerlendirmişlerdir (24).

$\mathrm{Bu}$ çalışmada incelenmiş olan diğer inflamasyon parametrelerine baktığımızda, 25(OH)D düzeyleri ile inflamasyon belirteçleri arasındaki ilişkilerin araştırıldığ geniş popülasyonlu kesitsel çalışmalarda ESR düzeylerinin incelenmediği görüldü. Bunun nedeninin ESR'nin akut faz reaksiyonuna yavaş yanıtı dolayısı ile inflamatuvar bir sürecin erken safhalarında yanlış negatif sonuçlar alınmasına yol açabileceğinin (25) bilinmesi olabileceği düşünüldü. $\mathrm{Bu}$ durum, çalışmamızda D vitamini eksikliği olarak $<20$ $\mathrm{ng} / \mathrm{mL}$ kabul edildiğinde $\mathrm{D}$ vitamini grupları arasında ESR yüksekliği açısından bir farkl11.k yok iken (Tablo 2), D vitamini eksikliği olarak $<30 \mathrm{ng} / \mathrm{mL}$ kabul edildiğinde ise D vitamini grupları arasında ESR yüksekliği açısından anlamlı bir fark ortaya çıkmasının (Tablo 3) sebebini de açıklayabilir.

Mellenthin ve ark. (20) yapmış oldukları çalışmada, 25(OH)D düzeyleri ve lökosit sayısı arasındaki ilişki lökosit sayısını etkilediği bilinen sigara içme değişkenine göre incelenmiş olup; 25(OH)D ile lökosit sayısı arasında sigara içmeyenlerde bir ilişki saptanmamış iken sigara içenlerde ters bir korelasyon olduğu saptanmıştır. Ek olarak, sigara içenler arasında 25(OH)D düzeyi düşük olanların lökosit sayılarının 25(OH)D düzeyi yüksek olanlara göre daha da artmış olduğunu 
tespit etmişlerdir (20). $\mathrm{Bu}$ bulgu, çalışmamızda tespit edilen lökosit yüksekliği olanların çoğunluğunda D vitamini eksikliği olması bulgusunu desteklemektedir. Diğer inflamasyon parametrelerine göre nispeten daha yeni araştırılmaya ve kullanılmaya başlanan N/L oranına baktığımızda, kesitsel olarak yine Türkiye'de yapılan bir diğer çalışmada da 25(OH)D düzeyleri ile N/L oranı arasında çalışmamıza benzer olarak ters yönlü zayıf düzeyde bir korelasyon tespit edilmiştir (26).

$\mathrm{Bu}$ çalışmanın kısıtlılığı olarak; incelenen parametreleri etkileyebilecek olan karıştırıcı değişkenlerin değerlendirilmemiş olmasıdır. Ancak bu yüzden yanlış değerlendirmelerin önüne geçebilmek adına incelenen parametrelerin düzeylerinin karşılaştırılmasından kaçınılmış olup, eksiklik ve yükseklik olarak değerlendirilmelerine gidilmiştir. Ayrıca çalışmaya dahil edilmiş olan vakaların D vitamini takviyesi alıp almadikları da bilinmemektedir ancak 49166 erişkini kapsayan bu çalışmadaki D vitamini eksikliği prevalansının eksiklik sınırı $<20$ $\mathrm{ng} / \mathrm{mL}$ kabul edildiğinde \%55,1, eksiklik sınırı $<30 \mathrm{ng} / \mathrm{mL}$ kabul edildiğinde ise $\% 84,6$ olarak yüksek seviyelerde olduğu görülmektedir. Bu bulgudan yola çıkarak D vitamini takviyesi alınıp alınmadığının çalışmanın sonuçları üzerine anlamlı bir etkisinin olmadığı düşünülmektedir. Ek olarak çalıșmanın örneklem büyüklüğü de karıștırıcı değişkenlerin etkisini azaltabilecek hatta yok sayllabilir düzeye getirebilecek yüksekliktedir.

$\mathrm{Bu}$ çalışmanın literatürdeki diğer çalışmalardan önemli farkı ise; henüz cevaplandırılamamış olan D vitamini düzeyleri ile inflamasyon arasındaki nedensonuç ilişkisine (tavuk-yumurta sorusu) kısmi bir yanıt getirmesidir. $\mathrm{Bu}$ çalışmada inflamasyon belirteci olarak incelenmiș olan CRP ve lökosit sayısı için geçerli olmak üzere; D vitamini eksikliği olanların çoğunluğunda inflamasyon belirteçlerinin yüksekliği yok iken, tam tersi olarak inflamasyon belirteçleri yüksek olanların çoğunluğunda ise D vitamini eksikliği olduğu tespit edildi (Tablo 2-3). D vitamini eksiklik sınırı 20'den $30 \mathrm{ng} / \mathrm{mL}$ 'ye çekildiğinde ise ek olarak ESR yüksekliği olanlarda da D vitamini eksikliğinin anlamlı düzeye geldiği ve her üç belirteç için de tespit edilen oranların her iki yönde de aynı kalmak üzere daha da arttıkları görülmektedir (Tablo 2-3).

\section{Sonuç}

Tüm bu bulgular, D vitamini düşüklüğünün inflamasyona neden olmasindan ziyade D vitamini düzeylerinin inflamasyonun sonucu olarak düşük olduğu hipotezini desteklemektedir.

\section{KAYNAKLAR}

1. Han QQ, Yu J. Inflammation: a mechanism of depression? Neurosci Bull. 2014;30:515-23.

2. Christodoulidis G, Vittorio TJ, Fudim M, et al. Inflammation in coronary artery disease. Cardiol Rev. 2014;22:279-88.

3. Taniguchi K, Karin M. IL-6 and related cytokines as the critical lynchpins between inflammation and cancer. Semin Immunol. 2014;26:54-74.

4. Skapenko A, Leipe J, Lipsky PE, et al. The role of the $\mathrm{T}$ cell in autoimmune inflammation. Arthritis Res Ther. 2005;7(Suppl 2):S4-14.

5. Cannell JJ, Grant WB, Holick MF. Vitamin D and inflammation. 2015;6:e983401.

6. Núñez J, Núñez E, Bodí $\mathrm{V}$, et al. Usefulness of the neutrophil to lymphocyte ratio in predicting longterm mortality in ST segment elevation myocardial infarction. Am J Cardiol. 2008;101:747-52.

7. Crowe FL, Jolly K, MacArthur C, et al. Trends in the incidence of testing for vitamin $\mathrm{D}$ deficiency in primary care in the UK: a retrospective analysis of

The Health Improvement Network (THIN), 2005 2015. BMJ Open. 2019;9:e028355.

8. Holick MF, Binkley NC, Bischoff-Ferrari HA, et al. Guidelines for preventing and treating vitamin D deficiency and insufficiency revisited. $J$ Clin Endocrinol Metab. 2012;97:1153-8.

9. Ross AC, Taylor CL, Yaktine AL, et al. Dietary reference intakes for calcium and vitamin D. Washington: National Academy of Sciences. 2010. 0-309-16394-3.

10. Autier P, Boniol M, Pizot C, et al. Vitamin D status and ill health: a systematic review. Lancet Diabetes Endocrinol. 2014;2:76-89.

11. Henriksen VT, Rogers VE, Rasmussen GL, et al. Proinflammatory cytokines mediate the decrease in serum $25(\mathrm{OH}) \mathrm{D}$ concentrations after total knee arthroplasty? Med Hypotheses. 2014;82:134-7.

12. Mangge H, Weghuber D, Prassl R, et al. The role of vitamin $\mathrm{D}$ in atherosclerosis inflammation revisited: more a bystander than a player? Curr Vasc Pharmacol. 2015;13:392-8. 
13. Guillot X, Semerano L, Saidenberg-Kermanac'h $\mathrm{N}$, et al. Vitamin D and inflammation. Joint Bone Spine. 2010;77:552-7.

14. Adorini L, Penna G. Control of autoimmune diseases by the vitamin D endocrine system. Nat Clin Pract Rheumatol. 2008;4:404-12.

15. Marcotorchino J, Gouranton E, Romier B, et al. Vitamin $D$ reduces the inflammatory response and restores glucose uptake in adipocytes. Mol Nutr Food Res. 2012;56:1771-82.

16. Mangin M, Sinha R, Fincher K. Inflammation and vitamin D: the infection connection. Inflamm Res. 2014;63:803-19.

17. Amer M, Qayyum R. Relation between serum 25hydroxyvitamin $\mathrm{D}$ and $\mathrm{C}$-reactive protein in asymptomatic adults (from the continuous National Health and Nutrition Examination Survey 2001 to 2006). Am J Cardiol. 2012;109:226-230.

18. Hyppönen E, Berry D, Cortina-Borja M, et al. 25Hydroxyvitamin D and pre-clinical alterations in inflammatory and hemostatic markers: a cross sectional analysis in the 1958 British Birth Cohort. PLoS One. 2010;5:e10801.

19. Ghashut RA, Talwar D, Kinsella J, et al. The effect of the systemic inflammatory response on plasma vitamin $25(\mathrm{OH}) \mathrm{D}$ concentrations adjusted for albumin. PLoS One. 2014;9:e92614.

20. Mellenthin L, Wallaschofski H, Grotevendt A, et al. Association between serum vitamin D concentrations and inflammatory markers in the general adult population. Metabolism. 2014;63:1056-62.

21. Murr C, Pilz S, Grammer TB, et al. Vitamin D deficiency parallels inflammation and immune activation, the Ludwigshafen Risk and Cardiovascular Health (LURIC) study. Clin Chem Lab Med. 2012;50:2205-12.

22. de Oliveira C, Biddulph JP, Hirani V, et al. Vitamin D and inflammatory markers: crosssectional analyses using data from the English Longitudinal Study of Ageing (ELSA). J Nutr Sci. 2017;6:e1.

23. Yang F, Sun M, Sun C, et al. Associations of Creactive Protein with 25-hydroxyvitamin D in 24 Specific Diseases: A Cross-sectional Study from NHANES. Sci Rep. 2020;10:5883.

24. Kruit A, Zanen P. The association between vitamin $\mathrm{D}$ and $\mathrm{C}$-reactive protein levels in patients with inflammatory and non-inflammatory diseases. Clin Biochem. 2016;49:534-7.

25. Osei-Bimpong A, Meek JH, Lewis SM. ESR or CRP? A comparison of their clinical utility. Hematology. 2007;12:353-7.

26. Akbas EM, Gungor A, Ozcicek A, et al. Vitamin $\mathrm{D}$ and inflammation: evaluation with neutrophilto-lymphocyte ratio and platelet-to-lymphocyte ratio. Arch Med Sci. 2016;12:721-7.

๑Copyright 2022 by Osmangazi Tıp Dergisi - Available online at tip.ogu.edu.tr $\odot T e l i f ~ H a k k ı ~ 2022$ ESOGÜ Tıp Fakültesi - Makale metnine dergipark.org.tr/otd web sayfasından ulaşılabilir. 